to be conducted downwards by horizontal planes in order to determine the lay of the strata. The currentbedded sand at the top of the excavation was recog. nized as part of the Upper Middle. It was devoid of bone or flint artifacts; but a thin seam of gravel running through it (A1 in Fig. 2) yielded numerous flint flakes, as did the thicker seam of gravel below $(B)$, which also contained a small hand-axe, two miniature cores and some bone fragments, as yet unidentified. The very loose sand with stones beneath contained few artifacts and no bone. Layers $A \mathbf{l}$ and $B$ were approximately horizontal in a west-northwest-enst-south-east direction, but at right angles showed a slight dip to the south-south-west.

On the second day of the excavation, in the westnorth-west end of the section, a thin band of very ochrous gravel was revealed with unstained gravel beneath it. This had a steep dip to the east-southeast and south-south-west. Immediately, several bone fragments and flint flakes were found. Further removal of material showed more inconsistent bands, also dipping but tending to converge upon the eastsouth-east. The grevel continued to be very rich in flint artifacts and bone fragments; many of the flint flakes were lustreless and sharp, as if freshly struck, others were slightly rolled. Excavation in this region was very difficult because of the proximaity of thiok, loose overlay, which tended to fall. A thicker band of dark, stained gravel was exposed beneath, and as this was being examined a small piece of bone showed through the lighter gravel at its base. The surrounding material was cleared away by the fingers and the new find, a right parietal, was exposed in silu, domo upwards. Its upper surface, at least, was seen to be in soft, soapy condition, and ancient cracks already existed. It was decided to cease all further work in order to decrease the probability of a fall of the disturbed material upon it, but to leave the bone in situ. Photographs were taken and a temporary protection of boards placed over the parietal in case of a dangerous fall; $\mathrm{Mr}$. Marston arrived two hours later and confirmed the discovery. A protective covering of plaster was made over the bone; but the loose nature of the gravel and the existing cracks defied attempts to extricate the fragment complete. All the pieces, however, were retrieved without damage to them and packed carefully in a box that was not opened again until arrival at the British Museum (Natural History) on August 2, save for the placing of a saturated wad of cotton-wool above to prevent any serious drying out.

Fig. 2 showg the conclusion of the excavation with the Lower Gravel ( $F)$ exposed, resting upon the tonacious Lower Loam $(G)$.
Mr. Marston confirmed that his occipital bone was found $51 \mathrm{ft}$. to the west-north-west of the new find and $49 \mathrm{ft}$. from the left parietal, the position of the three fragments forming a triangle with sides 51,49 and $24 \mathrm{ft}$. In his report on the discoveries ( $J$. Roy. Anthrop. Soc., 67, 350; 1937), his geological section agrees exactly with the new one figured, showing four oblique ochrous layers and, of great significance, the bottom one as the bone layer. The new fragment was barely one inch below this seam in the unstained sandy gravel, a difference of no importance in a river deposit. The only item of interpretation in which the now section differs from Mr. Marston's is that the layer of larger flints at the top of the gravel marked $F$ is considored to be the junction of the Lower and Upper Middle Gravels. Mr. Marston features the large flints but accepts the bottom ochrous band the bone layer) as the junction. The gravel of $F$ is more compact and darker than that of the looser, lighter gravel above it $(E)$, which contained bone fragments. No bone fragments were found in $F$.

A comparison of the two eections shows that there can be no doubt that the new right parietal was found in the same stratum as that in which $\mathrm{Mr}$. Marston found an occipital and left parietal in 1935-36. This renders the fact that all three fragments fit each other perfectly, belonging to the skull of the same individual, a little less remarkable.

Numerous bone fragments were found in association with the right parietal, and these are now at the British Museum for purposes of hardening and identification. It is hoped that they may add to the list of fauna from this level. Almost three hundred primary and finishing flint flakes were found during the excavation, of which only twelve showed signs of possible utilization. Four small, primitive handaxes were also found, typical of the Acheulian flint industry as represented at Swanscombe, as well as the point of a larger, finely finished hand-axe and a magnificent flake 'knife'. A full account of these artifacts will appear in the forthcoming report. Most of them were in a very sharp condition, with only a few minute ehippings along the edge and a lustre from rolling in the water. Many, however, are lustreless and virtually in mint condition. Although separated, the skull fragments show very little abrasion from rolling and there can be no doubt that the flint industry is contemporary.

Inside the triangle formed by the position of the three skull fregments recovered remains a mound, part of which is definitely undisturbed gravel of the skull zone. This area is now efficiently protected, and is to be excavated in the near future.

\title{
USE OF RADIOACTIVE MATERIALS IN BIOLOGICAL ASSAY
}

A JOINT meeting of the Soeiety for Analytical
the Society of Chemical Industry and the Chemical
Society was held during July 11 and 12 in the Bio-
chemistry Department of the University of Edin-
burgh ; the purpose of the meeting was a symposium
on "The Use of Radioactive Materials in Biological
Assay". Nine papers were read by invited speakers,
and the programme also included a dinner and a
visit to the Institute of Seaweed Research.
Public attention now being focused on the peaceful
uses of atomic energy and its by-products, it was porhaps not inappropriate that merabers of four learned societies should meet for the purpose of discussing some of the latest applications of the isotope technique to biological problems. Some epeakers, however, had obviousiy found difficulty in fitting the subject of their paper to the rather narrow field where biological assay and the applications of radio. active isotopes overlap. That the meeting was a success was in the main due to their interpreting the title of the symposium somewhat widely.

After a brief introductory address by Prof. G. F. Marrian, in which he recalled the pioneer work dono 
in the field of radioactive tracers by $G$. von Hevesy and his collaborators, the present writer gave an introductory paper on the determination of radio. active isotopes in biological samples. For the benefit of those not familiar with the instruments available for this purpose the first part of the paper was elementary in character, and was followed by an account of the more refined technique of gas-counting, by means of which the isotopes of carbon and hydrogen can be determined with high precision when present together in the same sample. A lively discussion followed, and most members present showed that they had an intimate knowledge not only of the virtues but more particularly the vices of many of the types of counter available. During the discussion on gas counting, Mr. F. P. W. Wintringham pointed out that ionization chambers used in conjunction with the most recent types of d.c. amplifiers are ultimately more sensitive than counters, but that they probably require more skill to operate and are not suited for use by assistant staff.

Dr. E. Lester Smith, of Glaxo Laboratories, Ltd., followed with a paper on the principles of isotope dilution assays. He exemplified the use of this valuable technique by means of an imaginary application to the determination of sodium chloride in sea water, and then enumerated the essential criteria for successful application of the technique. The most important of these is the isolation of a pure sample of the compound to be determined, once mixing with the labelled material is complete. This is sometimes very difficult, recrystallization to constant specific activity being often a laborious procedure. A useful application to the vitamin $\mathrm{B}_{12}$ field is the determination of the vitamin in crude fermentation liquors. These contain too many interfering substances for colorimetric or microbiological methods to be easily applied, but the problem has been solved by the use of vitamin $B_{12}$ labelled with cobalt-60. A known amount of known specific activity is added to the fermentation liquors, and a pure sample of the $B_{12}$ is isolated using resin-column chromatography. Ultimately the purified vitamin $B_{12}$ is counted in a liquid counter. The chief disadvantage of the method is the four-step purification procedure. In the course of his paper, Dr. Lester Smith also referred to more sophisticated applications of the technique, mentioning in this connexion the use of labelled reagents, for example, iodopiperonyl chloride labelled with iodine-131 for the determination of amino-acids in protein hydrolysates. $\mathrm{He}$ also referred to the reversed isotope dilution technique, in which the total amount of a labelled constituent of a mixture is determined by adding a known weight of unlabelled substance, re-isolating it and determining its specific activity. From this and from the weight added, the total activity of the substance in the mix. ture can be calculated. 'I'his is sometimes referred to as the carrior technique, and as such was more familiar to some members of the audience.

Another practical application of the technique to what might be termed a commercial problem was described by Mr. G. C. Ashton, also of Glaxo Laboratories. This problem is the determination of penieillin $G$ (benzylpenicillin) in fermentation liquors. These contain also other penicillins and other antibiotics which virtually rule out microbiological assay. Methods are available in the literature for the preparation of deuterium- or ${ }^{13} \mathrm{C}$-labelled penicillin $C_{x}$ suitable for isotope dilution applications; but the deuterium-labelled penicillin in particular is too costly and laborious to produce with a sufficiently high isotopic abundance for practical applications. (This consideration does not, of course, apply to tritium, which is not only cheaper than deuterium but also cheaper than carbon-14.) In the method described, the ${ }^{14} \mathrm{C}$-labelled material is prepared by standard procedures. Known activities are added to the fermentation liquors and penicillin $G$ isolated and its specific activity determined. It was in the accuracy claimed for his radioassays that $\mathrm{Mr}$. Ashton provoked most discussion, his claims for closer than 5 per cent agreements between replicates being questioned by some speakers. His assertion that the counting rate of thick samples continues to increase beyond the usually accepted infinite thickness value was confirmed by Dr. W. F. Pover, of Birmingham, and was attributed to edge effects.

Dr. A. S. McFarlane, of the National Institute for Medical Research, Mill Hill, gave an account of the preparation and research applications of radio. iodinated plasma proteins. It has been found that if the protein molecules contain not more than ten atoms of iodine per molecule, they are unchanged antigenically. More than ten atoms iodine por molecule produces an antigenically different protein with different crystalline properties. When radioiodine is used, it is not sufficient to have an average of less than ten atoms iodine per protein molecule : steps must be taken to see that no appreciable proportion of the molecules contains more iodine than this because, having different chemical properties, and, in consequence of the high iodine content a relatively high specific activity, their presence will give rise to erroneous results. The practice at Mill Hill, where radioiodinated proteins are prepared, is therefore to use iodine-131 in the proportion of one atom per protein molecule, and to carry out the reaction under conditions that will ensure uniform reaction. Proteins react very rapidly with iodine at alkaline $p \mathrm{H}$, one molecule of hydrogen iodide being eliminated for each iodine atom attached. Fast mixing is therefore necessary, and this is achieved by means of a microjet apparatus in which jets of protein solution and iodine solution flowing in opposite directions meet in a minute mixing chamber. The yield is usually of the order of 60 per cent of the theoretical, and the product is purified on an ionexchange resin. The final solution as made available for research is isotonic, noutral, sterile and with less than 1 per cent of the radioactivity in the form of iodide ion.

Experiments have been carried out to ensure that the labelled plasma proteins so prepared cannot be 'recognized' by experimental animals. This work has been done by comparing the specific activity - time curves of radioiodinated proteins and biosynthetic ${ }^{11} \mathrm{C}$-labelled proteins. These were prepared by feeding high-specific activity ${ }^{14} \mathrm{C}$-algal protein to rabbits and then isolating the plasma proteins. It was found that the two curves nearly coincide, the difference between them being of very doubtful significance. A useful property of the radioiodine-labelled proteins is that the label is not re-utilized as is carbon-14. Whereas the motabolic products of ${ }^{14} \mathrm{C}$-labelled proteins are re-incorporated into new proteins, the iodine-131 is rapidly excreted once the protein has been degraded. This has the practical advantage that only tho protein administered is being traced.

The application of an isotope technique to the assay of aldosterone and other steroids was described in a paper by Mr. R. N. Jones, Mrs. S. A. Simpson 
and Dr. J. F. Tait, of the Middlesex Hospital, London, and read by Dr. Tait. The assay method is based upon changes in the sodium-potassium ratio in adrenalectomized rats caused by certain adrenal hormones, notably deoxycorticosterone and aldosterone. Two short-lived isotopes, sodium-24 and potassium-42, of half-lives $15 \cdot 06$ and $12 \cdot 4 \mathrm{hr}$., respectively, can be employed for this purpose. The technical problem which has to be met in this work is either the measurement of each isotope separately in the presence of the other, or the measurement of the ratio itself. This latter alternative has been found by these workers to be the better, and the method used is based on the fact that, whereas an absorber of thickness $300 \mathrm{mgm} . / \mathrm{cm}$. placed between the sample and the counter reduces the observed counting rate due to sodium-24 by a factor of 20 , it reduces that due to potassium-42 by a factor of only 3 . This fact ean be applied successfully to the measurement of sodium-24/potassium-42 ratios, and carries with it the advantage that whereas both isotopes decay rapidly, the ratio does not because they both have very nearly the same half-life.

The assay is carried out by reference to a graph of the logarithm of the ratio plotted against the logarithm of the dose of steroid. Aldosterone is found to be 120 times more potent than deoxycorticosterone, which is used as a standard. The method, although very successful, was compared by Dr. Tait with a non-isotopic method, namely, the measurement of sodium-potassium ratios by flame photometry, and the opinion was expressed that in the long run the non-isotopic method would probably prove to be preferable.

Isotope dilution methods for the determination of cortisol and aldosterone, using the technique according to the principles described by Dr. Lester Smith, were also described. Ring-labelled cortisol and aldosterone di-(1-14C)-acetate were used. The chief difficulty was in the purification of the extracted compounds, column chromatography being used.

The use of iodine-131 for another bio-assay was described by Mr. Trevor Kinnear of Edinburgh, whose paper was concerned with the assay of thyroidstimulating hormone. His method is based on the effect of the hormone on clearance of labelled iodine from the thyroids of day-old cockerels. The chicks are injected first with iodine-131 and then, for several days following, with the sodium salt of thyroxine. Control groups are then injected with saline and other groups with various amounts of the hormone preparation to be assayed. The change in activity of the thyroids as measured in vivo indicates the rate of clearance of labelled iodine and is a measure of the activity of the thyroid-stimulating preparations.

Another method in which radioiodine is used was described in a paper by Mr. F. W. Jennings and Dr. W. Mulligan, of Glasgow. Their problem is to measure the volume of intracellular plasma in centrifuged red cells. Hæmatrocrit values as determined by the conventional methods are found to give very variable results, especially with the blood of cows and sheep. The isotope method adopted was based on the use of plasma proteins labelled with iodine-131 and subsequent measurement of the residual activity in the centrifuged cells. Variable results were still obtained with cows and sheep; but these were traced to the effect of temperature and time of centrifuging. More uniform results were obtained by the use of cooled centrifuges, the temperature being controlled at $15^{\circ}$.
Mr. F. P. W. Wintringham, of the Pest Infestation Laboratory, gave an account of some of the methods employed for investigating the biochemistry of toxic action in insects. His experimental animal is the common house fly, and at least one of his audience envied him the convenience of the size of his subjects, and admired the technique devised for experimenting upon them. Mr. Wintringham first pointed out that, in general, there are many dangers attendant upon the use of in vitro techniques, especially when toxic action is to be investigated. A given agent may inhibit particular enzymes in vitro, whereas in the living animal it may either never reach that enzyme or it may reach it by pathways which are absent in in vitro preparations. Since the well-being of the whole animal depends on the existence of metabolic pools the components of which are each within a particular range of concentrations, toxins cause accumulations or depletions of various components of these pools. It is to the study of metabolic pools and the action upon them of certain known toxins that an isotope technique coupled with paper chromatography has been successfully applied.

Mr. Wintringham took for his example the labelling of metabolic pools with phosphorus-32. When carrierfree ${ }^{32} \mathrm{P}$-phosphate is administered to the fly, all the metabolically active phosphorus-containing organic compounds become rapidly labelled. The fly is then killed and tissue extracts separated on paper chromatograms, and their presence and specific activities determined by scanning techniques. The effect of toxins on the labelling pattern is often spectacular. For example, the effect of methyl bromide is a large diminution in the size of the adenosine triphosphate pool and an increase in the size of the inorganic phosphorus pool. Cyclopropane, on the other hand (which is used as an anæsthetic during the injection of the flies), has no such effect. An interesting refinement of the technique is the confirmation of the specific activity of the phosphorus compounds : the original phosphorus-32 activity is allowed to decay away and the papers are irradiated in the pile, when all the phosphorus in the spots becomes radioactive by the ${ }^{31} \mathrm{P}(n, \gamma)^{32} \mathrm{P}$ reaction, thus giving, by its radioactivity, a measure of the amounts of phosphorus in the spots as would have been found by a chemical determination. By this means the interesting fact was confirmed that all the phosphorus atoms of adenosine triphosphate are labelled when phosphorus-32 is injected into house flies, whereas in mammalian tissues only the $\beta$ - and $\gamma$-atoms are usually found to be radioactive. In answer to a question, however, Mr. Wintringham expressed the view that this does not constitute an important qualitative difference between the metabolism of insects and mammals, but is merely a reflexion of the higher turnover-rates in insects. He believes that, given time, all the phosphorus atoms of adenosine triphosphate in animal tissues would be exchanged; in fact, the similarities between the biochemical pathways of rats and flies are more striking than the differences.

The concluding paper of the meeting was a survey by Dr. J. F. Loutit of the dangers to health entailed in the manipulation of radioactive substances. In general, he was reassuring: only activities greater than I me. of $\gamma$-ray emitters need be regarded as a danger so far as external radiation of workers is concerned, and these dangers can be controlled by the use of pocket dosimeters or film badges. Blood counts are much less satisfactory than such physical 
methods of measurement. Blood counts remain more or less constant until the subject has had a sufficient dose to produce irreversible damage and no institution in Great Britain now relies solely on this method of control. The dangers from internal radiation, which arise only when radioactive materials are inhaled or eaten, in general entail similar risks : that is to say, quantities of the order of $1 \mathrm{mc}$. inside the body are to be regarded as dangerous. But here, of course, the chemical properties of the isotope, which determine where it is deposited and how fast it is eliminated, its half-life and the nature of its radiations are also important considerations in assessing the dangers. The bone-seeking isotopes such as strontium are by far the most dangerous, as they irradiate the bone marrow. In concluding, and in answer to questions, Dr. Loutit expressed his opinion that emitters of soft $\beta$-radiation such as carbon-14, tritium and sulphur-35 are not particularly dangerous, and procautions similar to those taken by bacteriologists when dealing with pathogenic organisms would protect workers. He reminded the audience, however, that whereas pathogenic organisms accidentally let loose in the laboratory can be destroyed by disinfectants or other agents, radioactivity cannot be destroyed.

In attempting to assess the value of the meeting, the present writer is under a difficulty. A symposium devoted to technique rather than to a field of research brings together workers on very different subjects, whose common interest hangs on the somewhat slender thread of common technique. A smaller proportion of those attending the meeting are therefore able to comment pertinently on each piece of research than occurs when the subject is common to all. There can be no doubt, however, that the meetings were much enjoyed by those present.

R. F. Glascock

\section{NEWS and VIEWS}

Textile Chemistry at Manchester :

Prof. R. H. Peters

THw Manchester College of Technology has trained students of textile chemistry ever since 1905, and the pioneer work of Prof. Knecht, of J. Huebner and of F. Scholefield is well known. The industry has always found great difficulty in recruiting skilled technologists, and it has somotimes failed for years to make full use of discoveries which have been made by the big firms and by research associations such as the Shirley Institute and the British Rayon Research Association. It is possible that if the textile industry of Britain could exploit the new synthetic fibres and the now methods of dyeing and finishing, it might have a chance of re-establishing something of its former position of pre-eminence in those world markets in which it cannot compete so long as it restricts itself to traditional fibres and the oldfashioned techniques which are now so well known to its competitors.

The appointment of Dr. Raymond Harry Peters to be the first professor of textile chemistry in the Manchester College of Technology may therefore prove to be of great importance to the textile industry as a whole. Dr. Peters obtained the degree of bachelor of science with first-class honours in chemistry at King's College, London, in 1939 and took his Ph.D. in 1942. He was in the Dyestuffs Division of the Imperial Chemical Industries, Ltd., at Blackley during 1941-47. He took a degree in mathematics in the University of Manchester in 1949 and then returned to Blackley. He became head of the Dyeing Research Section of I.C.I. in 1952. He has published a number of scientific papers and in 1953 he was awarded the medal of the Worshipful Company of Dyers. Prof. Peters will have at his disposal a splendid new dyehouse which has been very well equipped, thanks to the generosity of Courtaulds and the co-operation of a number of firms, in particular Messrs. Mather and Platt, Ltd. He should be able to build up a strong postgraduate research school in co-operation with local industry, and it is much to be hoped that his department will attract students who can be trained in this vitally important branch of technology, and so help the textile industry of Britain to bring itself up to date.

\section{Electrical Engineering at Swansea :} Prof. W. Fishwick

THE chair of electrical cngineering which was recently established at the University College of Swansea has been filled by the appointment of $\mathrm{Dr}$. W. Fishwick, who is at present a lecturer in engineering in the University of Edinburgh. After obtaining first-class honours in the Mechanical Sciences Tripos at Cambridge in 1940, together with the Wynne Prize from Pembroke College, Dr. Fishwick joined the staff of the Telecommunications Research Establishment, where he was concerned first with the development of radar equipment and later with radio counter-measures. In 1944 he was commissioned for special duties with the R.A.F. and commanded a scientific intelligence unit operating in North-West Europe. Dr. Fishwick returned to Cambridge in 1946 as a research student under Prof. E. B. Moullin and Mr. C. W. Oatley, where he developed a novel type of mass-spectrometer using radar techniques which was capable of following very rapid changes in gas composition. Upon the completion of this work, for which Dr. Fishwick was awarded the degree of Ph.D., he took up a post with Imperial Chemical Industries, Ltd., at Manchester in 1948, where he was placed in charge of a laboratory for the develop. ment of instruments concerned with the automatic control of chemical plant. Two years later he was appointed to his present post at Edinburgh. Dr. Fishwick's more recent researches have been concerned with automatic control theory and with certain machine-tool vibration problems. It is peculiarly appropriate that the first occupant of the new chair should be actively interested in the field of automatic control, for many of the steel, chemical and other plants which are situated in the immediate neighbourhood of Swansea make extensive use of such controls.

\section{Social Responsibilities of Scientists}

IN a paper presented to the American Philosophical Society (American Scientist, 43; July 1955), Prof. J. H. Hildebrand, of the University of California, examines the social responsibility of scientists. They should first try to extend the boundaries of knowledge and be able to answer Benjamin Franklin's question, 